\title{
Role of bronchoalveolar lavage in the evaluation of interstitial pneumonitis in recipients of bone marrow transplants
}

\author{
HEATHER J MILBURN, H GRANT PRENTICE, R M DU BOIS \\ From the Departments of Thoracic Medicine and Haematology, Royal Free Hospital, London
}

ABSTRACT Forty episodes of pneumonitis in 30 recipients of allogeneic bone marrow transplant: were investigated by fibreoptic bronchoscopy and bronchoalveolar lavage. A positive diagnosis wag made in 32 episodes of pneumonitis (24 patients), giving a diagnostic yield of $80 \%$. In 31 of these the diagnosis was made within 24 hours of bronchoscopy and this enabled the appropriate treatment to be instituted early. Eighteen patients recovered from their primary infection, althoug $\vec{P}$ two died subsequently of respiratory failure due to postpneumonic lung destruction. Ten patients later developed a second episode of pneumonitis and a diagnosis was made in nine of these. Only three survived a second episode. Bronchoalveolar lavage was well tolerated by all patients and therê was no morbidity or mortality that could be directly attributed to the procedure. Bronchoalveolap lavage is a safe and valuable early diagnostic procedure for the investigation of pulmonary compli cations in patients who have received bone marrow transplants.

Pulmonary complications are major causes of morbidity and mortality in patients who have received bone marrow transplantation. ${ }^{12}$ In some series ${ }^{13-5}$ as many as half of these patients have suffered from a major pulmonary problem in the six months immediately after transplantation and up to $70 \%$ of these (or $35 \%$ of all patients receiving transplants) have died from this complication. ${ }^{13-5}$ If results are to be improved, a diagnosis must be made early with a technique that has few important complications itself and results in the institution of successful treatment. Bronchoalveolar lavage has been found to be a safe and effective method of sampling peripheral lung tissue $^{6}$ and has been used to aid diagnosis in heterogeneous populations of immunosuppressed patients, ${ }^{78}$ patients with renal transplants, ${ }^{9}$ and patients with the acquired immune deficiency syndrome (AIDS). ${ }^{1011}$ Studies of heterogeneous groups of patients may be unhelpful in planning management within a homogeneous group. Furthermore, the value of bronchoalveolar lavage as the sole method of investigation of pneumonitis in a homogeneous population of patients who have received bone marrow

Address for reprint requests: Dr R M du Bois, National Heart, Lung, and Blood Institute (Building 10), Bethesda, Maryland 20892, USA.

Accepted 27 March 1987 transplants has not previously been reported. For these reasons we have investigated 30 recipients of allogeneic bone marrow transplants who developed clinical evidence of pneumonitis.

\section{Methods}

\section{PATIENTS}

Forty consecutive episodes of suspected pneumonitis (defined as inflammation, as judged by clinical, radio-o logical, or physiological signs, in the peripheral air spaces) were investigated in 30 recipients of allogeneico bone marrow transplants. Nineteen patients were male and ages ranged from 12 to 47 (median 27) years. The pretransplant haematological diagnosesn are outlined in table 1 . Treatment regimens used to induce remission varied between individuals; but the 0 drugs commonly used were daunorubicin, cytosine arabinoside, and 6-thioguanine for acute myeloid leu-0으 kaemia (AML); vincristine, prednisolone, daunorubi cin, L-asparaginase, etoposide (VP16/213), thioguanine, methotrexate, and 6-mercaptopurine for + acute lymphoblastic leukaemia (ALL); and busulphan or hydroxyurea, or both, for chronic granu-O locytic leukaemia (CGL). All patients received T cello depleted bone marrow from matched $(n=23)$ or par $-\overrightarrow{\mathbb{D}}$ tially matched $(n=7)$ sibling donors. All later devel-o oped clinical features of pneumonitis (table 2). Most 
Table 1 Pretransplant haematological diagnoses in the 30 patients

\begin{tabular}{lll}
\hline Disease & Stage & $\begin{array}{l}\text { No of } \\
\text { patients }\end{array}$ \\
\hline Acute lymphoblastic & Remission & 6 \\
leukaemia & Relapse & 1 \\
Acute myeloid leukaemia & Remission & 8 \\
& Relapse & 4 \\
Chronic granulocytic & Chronic phase & 9 \\
$\quad$ leukaemia & Accelerated phase & 1 \\
Myelofibrosis & - & 1 \\
\hline
\end{tabular}

patients developed first episodes of pneumonitis 40-120 days after transplantation. Eight patients of those who developed second episodes did so in the first year after transplantation. One patient suffered a second episode during the second year and one during the third year after transplantation. In the three instances in which chest radiographs were normal, a diagnosis of pneumonitis was made on the basis of the development of cough, breathlessness, and lower transfer factor (TLCO) values than earlier after transplantation.

\section{PRETRANSPLANT CONDITIONING AND}

\section{TRANSPLANT}

Patients with AML in the first complete remission, all those with CGL who received HLA matched transplants, and a patient with myelofibrosis were given two doses of cyclophosphamide $60 \mathrm{mg} / \mathrm{kg}$ body weight on days -4 and -3 and total body irradiation on day 0 . The average dose to the lung was $670-830$ cGy (rad). All patients with ALL and patients receiving mismatched transplants were given two doses of cyclophosphamide $45 \mathrm{mg} / \mathrm{kg}$ body weight on days -4 and -3 plus six doses of cytosine arabinoside $3 \mathrm{mg} / \mathrm{m}^{2}$, with total body irradiation as above.

Immediately after transplantation all patients were isolated in reverse barrier nursing conditions and were given prophylactic acyclovir, ketoconazole, and amphotericin suspension together with gut decon- tamination using neomycin and colistin. Co-trimoxazole, as prophylaxis against Pneumocystis carinii infection, was added when the neutrophil count rose above $1 \times 10^{9} / \mathrm{ml}$.

\section{SAMPLE COLLECTION}

Bronchoalveolar lavage was performed using an Olympus BF1T fibreoptic bronchoscope. The upper airways were anaesthetised with $10 \%$ lignocaine topical spray and $2 \mathrm{ml}$ of $4 \%$ lignocaine were applied to the vocal cords under direct vision. Aliquots of $2 \%$ lignocaine were used to anaesthetise the lower respiratory tract. Supplemental oxygen was administered at a rate of $41 / \mathrm{min}$ throughout and for four hours after the procedure.

The bronchoscope was wedged into the orifice of a subsegmental bronchus of the middle lobe or lingula in patients with either normal chest radiographs or diffuse radiological changes. Where chest radiographs showed local changes the appropriate segment was lavaged. Bronchoalveolar lavage was performed with $3 \times 60 \mathrm{ml}$ aliquots of normal saline warmed to $37^{\circ} \mathrm{C}$ and buffered to $\mathrm{pH} 7.4$ by the addition of $175 \mu \mathrm{Eq}$ $(\mu \mathrm{mol})$ of sodium bicarbonate to $500 \mathrm{ml}$ normal saline. Each aliquot was aspirated immediately after its instillation into silicon coated glass bottles maintained at $4^{\circ} \mathrm{C}$.

\section{PROCESSING LAVAGE SAMPLES}

All lavage samples were investigated by routine Gram staining bacterial, culture and staining and culture for mycobacteria. Samples were also stained with Grocott's silver stain to detect fungi and Pneumocystis carinii. The lavaged cells were examined cytologically. For viral studies the fluid was inoculated into cultures of human lung embryo fibroblasts. Samples were also investigated for cytomegalovirus by using the detection of early antigen fluorescent foci (DEAFF) test. This technique has been fully described elsewhere. ${ }^{12}$ In addition, samples of lavage fluid were centrifuged at $350 \mathrm{~g}$ for 10 minutes and aliquots of the cell pellet were stained directly with monoclonal antibodies raised against cytomegalovirus protein. ${ }^{12}$

Table 2 Clinical, radiological, and physiological features of 30 patients with 40 episodes of pneumonitis after bone marrow transplantation

\begin{tabular}{|c|c|c|c|c|c|c|c|}
\hline \multicolumn{7}{|c|}{ Number of patients } & \multirow{2}{*}{$\begin{array}{l}\mathrm{PaO}_{2}(\mathrm{kPa}) \\
\text { in room air } \\
(n=13)\end{array}$} \\
\hline $\begin{array}{l}\text { Symptoms } \\
(n=40)\end{array}$ & & $\begin{array}{l}\text { Signs } \\
(n=40)\end{array}$ & & $\begin{array}{l}\text { Radiograp } \\
(n=40)\end{array}$ & shadowing & $\begin{array}{l}\text { Transfer factor } \\
(n=29)\end{array}$ & \\
\hline $\begin{array}{l}\text { SOB } \\
\text { Cough } \\
\text { Sputum } \\
\text { Haemoptysis }\end{array}$ & $\begin{array}{r}40 \\
21 \\
1 \\
1\end{array}$ & $\begin{array}{l}\text { Fever } \\
\text { Wheeze } \\
\text { Crackles } \\
\text { None in lung }\end{array}$ & $\begin{array}{r}38 \\
4 \\
26 \\
10\end{array}$ & $\begin{array}{l}\text { Localised } \\
\text { Diffuse } \\
\text { Normal }\end{array}$ & $\begin{array}{r}18 \\
19 \\
3\end{array}$ & $\begin{array}{l}\text { Reduction by } \\
>20 \% \text { of } \\
\text { pred value }\end{array}$ & $\begin{array}{l}\text { Mean } 7.9 \\
\text { Range } 5 \cdot 1-12 \cdot 9\end{array}$ \\
\hline
\end{tabular}

$\mathrm{SOB}$ - short of breath; $\mathrm{PaO}_{2}$ - arterial oxygen tension. 


\section{Results}

A diagnosis was made in 32 of the 40 episodes of pneumonitis by lavage alone. No diagnosis was made from eight lavages, but in four cases the patients recovered rapidly with antimicrobial treatment that had already been started empirically before bronchoscopy and a presumptive diagnosis of a treated bacterial infection was made. One patient underwent open lung biopsy but this also failed to help with diagnosis. In the remaining three cases the patients died without a diagnosis of their pulmonary problem. Postmortem examination of two of these patients also failed to provide a diagnosis of their condition, which was finally termed idiopathic pneumonitis. Postmortem examination of the third patient produced samples from which a diagnosis of giant cell pneumonitis was made. The histological appearances were similar to those seen in measles pneumonitis, but the virus was never isolated. The diagnostic sensitivity of bronchoalveolar lavage in this series was therefore $86 \%(32 / 37)$.

\section{INFECTIVE AGENTS ISOLATED}

The types of infection in the 32 positive lavage samples are shown in tables 3 and 4 . More than one pathogen was isolated from the lavage fluid from four patients. The most common pathogen found was cytomegalovirus, which was present in 20 lavage samples ( 15 patients); in four cases it was found in association with other microorganisms. Of these 20,19 were positive by DEAFF and two also on direct staining of the lavage cells. The twentieth was negative by DEAFF and direct staining but was positive in conventional cell culture, and this was the only result that was not available either on the day of bronchoscopy or the following day.

DEAFF was also performed on the saliva of 29 patients on the day of bronchoscopy. Only two patients out of the 14 with cytomegalovirus present in the lavage fluid also had cytomegalovirus in the saliva; it was also present in the saliva of two out of 15 patients in whom no cytomegalovirus was detected if the lavage fluid.

All samples were put up in cultures of human lun embryo fibroblasts. No other viruses were identifie by this method in this group of patients and severas problems were encountered with the technique. Fouf of the cultures became contaminated with bacteria and fungi during their three week incubation and three others were also of no diagnostic use owing t $\overrightarrow{\mathrm{e}}$ toxicity of the fibroblasts. This latter problem is paro ticularly troublesome with bronchoalveolar lavag. fluid, although it may also occur to a lesser extent with samples of blood, urine, and saliva. In addition:cultures had to be incubated for 5-21 days for detection of cytomegalovirus.

Pneumocystis carinii was isolated from four lavage samples, in two in association with cytomegalovirus. The bacteria found were Staphylococcus aureus and Pseudomonas aeruginosa. Two patients had repeate infections with these organisms despite appearing t\$ recover from the first episode. Fungi were isolated from a total of five lavage samples. In one case Aspers gillus fumigatus was found in association with cyto:megalovirus, and in another cryptosporidial oocytes were found concurrently with cytomegalovirus. Leus kaemic relapse was diagnosed by lavage in on patient.

There was no relationship between type of radio logical abnormality and pathogen isolated. Patient with cytomegalovirus in particular presented witi diffuse, focal, and normal chest radiographs.

\section{RESPONSE TO TREATMENT}

The results from lavage were available on either the same or the following day in all except one case, and this meant that appropriate changes could be made to treatment within 24 hours of bronchoscopy. Eleven op the 12 patients with a first episode of cytomegalovirus pneumonitis were diagnosed by the DEAFF tes within 24 hours; 10 of these were treated with cytoo megalovirus hyperimmune globulin and the eleventh with Sandoglobulin and the antiviral agent Gan

Table 3 Results and outcome after first episode of pneumonitis in 30 patients

\begin{tabular}{|c|c|c|c|c|}
\hline $\operatorname{Organism}(s)$ & No of patients & $\% B A L$ diagnoses & No of survivors & $\begin{array}{l}\text { No developing } \\
\text { second infection }\end{array}$ \\
\hline $\begin{array}{l}\text { CMV } \\
\text { CMV and Pneumocystis carinii } \\
\text { CMV and Aspergillus fumigatus } \\
\text { Pneumocystis carinii } \\
\text { Bacteria: Staphylococcus aureus } \\
\quad \text { Pseudomonas aeruginosa } \\
\text { Fungi: Candida albicans } \\
\text { Aspergillus fumigatus } \\
\text { Leukaemic relapse } \\
\text { No diagnosis }\end{array}$ & $\begin{array}{r}12 \\
2 \\
1 \\
2 \\
2 \\
1 \\
1 \\
1 \\
1 \\
7\end{array}$ & $\begin{array}{r}40 \\
7 \\
3 \\
7 \\
7 \\
3 \\
3 \\
3 \\
3 \\
23\end{array}$ & $\begin{array}{l}7 \\
0 \\
0 \\
1 \\
2 \\
1 \\
1 \\
0 \\
0 \\
5\end{array}$ & $\begin{array}{l}6 \\
- \\
1 \\
1 \\
\frac{1}{-} \\
\frac{1}{1}\end{array}$ \\
\hline
\end{tabular}


Table 4 Results and outcome of second episode of pneumonitis in 10 patients

\begin{tabular}{llll}
\hline Organism & No of patients & No of survivors & Original organism \\
\hline CMV & 4 & 3 & CMV 4 \\
CMV and Cryptosporidium & 1 & 0 & CMV \\
Bacteria: Staphylococcus aureus & 1 & 0 & Saureus \\
$\quad$ Pseudomonas aeruginosa & 1 & 0 & aruginosa \\
Fungi: Candida albicans & 1 & 0 & Pneumocystis carinii \\
No diagnergillus fumigatus & 1 & 0 & None found \\
Nosis & 1 & 0 & CMV \\
\hline
\end{tabular}

CMV-cytomegalovirus.

ciclovir (BW759U, DHPG). Seven patients survived this first episode but six of them went on to develop a second episode (table 3). The patient who was not diagnosed within 24 hours was not treated for cytomegalovirus pneumonitis and died. Two patients had cytomegalovirus and Pneumocystis carinii infections and one recovered from the infection, but he sustained considerable lung damage and later developed bilateral pneumothoraces resistant to treatment; and he subsequently died. One patient recovered from $P$ carinii alone, and one from Candida albicans. Three patients with bacterial infections recovered from a first episode.

A diagnosis of an initial infection was made by bronchoalveolar lavage in 22 patients (table 3) and 12 of these survived $(55 \%)$. A further five in whom no organism was isolated also survived. Ten of these 17 survivors, however, later relapsed after successful treatment of their first infection. The time taken to relapse varied from three weeks (two patients) to two years three months but most patients remained well for from two to eight months between episodes. The two patients who relapsed after only three weeks had initially responded to treatment with clearing of the chest radiograph, reduced temperature, and improvement in symptoms and signs; but this response was short lived, and when they did relapse deterioration was swift and both died. The other eight patients recovered completely between episodes, with gradual improvement in pulmonary function in addition to the other indices.

Three patients recovered completely from a second episode of interstitial pneumonitis and in all three both episodes were due to infection with cytomegalovirus (table 4).

In the 30 patients studied there were 40 episodes of pneumonitis and recovery followed 20 of these $(50 \%)$. Thirty one of these 40 episodes were due to infection diagnosed by bronchoalveolar lavage and recovery followed 15 of these individual episodes of infection $(48 \%)$. At the end of the study a total of 10 of the 30 patients $(33 \%)$ had survived episodes of pneumonitis and three of these had overcome two infections with cytomegalovirus.

\section{COMPLICATIONS OF THE PROCEDURE}

Bronchoalveolar lavage was well tolerated by all patients, even those who were already extremely unwell. There was occasional contact bleeding in those whose platelet counts were below $20 \times 10^{9} / 1$ but this was minimised by the infusion of platelet concentrate both before and during the procedure. Two children had their bronchoscopies under general anaesthesia and a further four patients had them while being ventilated for respiratory failure. Bronchoscopy and lavage were performed easily via the endotracheal tube without appreciably compromising ventilation. No morbidity or mortality could be directly attributed to the lavages.

\section{Discussion}

This study describes pulmonary infections diagnosed by bronchoalveolar lavage alone that were encountered in a homogeneous group of recipients of bone marrow transplants and the subsequent outcome of these patients after prompt diagnosis and treatment. The success of bone marrow transplant programmes has been hampered by diverse and serious pulmonary complications. These problems are common $^{151314}$ and result in considerable morbidity and mortality. The distinction between infective and non-infective processes is rarely clear on the basis of clinical criteria alone. In addition to infection, lung damage can result from graft versus host disease, irradiation, and previous drug treatment used to induce remission. Furthermore, leukaemic relapse may itself present as pneumonitis. Since patients have received $T$ cell depleted bone marrow, graft versus host disease is no longer a major problem in our unit ${ }^{15}$ and we have found that infection is the greatest cause of morbidity and mortality. The infections seen include those caused by bacteria, especially the Gram negative group, fungi, protozoa, and viruses. The prophylactic use of ketoconazole and co-trimoxazole has reduced the incidence of some of these infections, and acyclovir has significantly reduced the problems due to herpes simplex and varicella zoster viruses but has had no impact on the incidence of cytomegalovirus infection. Cytomegalovirus remains the most com- 
mon pathogen encountered in our unit.

It is important to make an early diagnosis of pulmonary infection in the immunocompromised patient as rapid diagnosis allows the early institution of appropriate treatment and changes to treatment which has been started empirically. Drugs that may be toxic (including those with known toxicity to the bone marrow) can be added with confidence once a positive diagnosis is made, and in our study four patients could begin treatment with co-trimoxazole and two with amphotericin. Three of these patients survived their infection. Infections with cytomegalovirus are associated with $>90 \%$ mortality $^{5}$ and, until recently, a diagnosis of cytomegalovirus pneumonitis was not particularly helpful as no effective therapeutic agents were available. Recent reports, however, indicate that cytomegalovirus hyperimmune globulin and some of the new antiviral agents have been used successfully in some patients ${ }^{1617}$; so it is now just as important to diagnose cytomegalovirus early in the course of the infection as it is to diagnose infections due to bacteria, $P$ carinii, and fungi. Early diagnosis also means that in the future new antiviral agents can be assessed.

Several techniques have been advocated for diagnosing interstitial pneumonitis in immunocompromised patients. ${ }^{18-23}$ Diagnostic yields are variable and serious complications have been reported with transtracheal aspiration, ${ }^{23-25}$ transbronchial biopsy, ${ }^{26-28}$ percutaneous needle biopsy, ${ }^{29} 30$ and open lung biopsy. ${ }^{19}$ The problems associated with these techniques are both more frequent and more severe in patients with refractory thrombocytopenia and in those being mechanically ventilated. Most of our patients had platelet counts below $40 \times 10^{9} / 1$; four were being mechanically ventilated and two had to have bronchoscopy under general anaesthesia. For these reasons we considered that biopsy techniques were inappropriate and confined our invasive investigations to bronchoalveolar lavage. A positive diagnosis was made in 32 out of the 40 episodes of pneumonitis $(80 \%)$, a yield that compares favourably with the results from other centres where lavage has been used to investigate mixed groups of immunosuppressed patients, ${ }^{810}$ patients with acquired immune deficiency syndrome (AIDS), ${ }^{1011}$ and recipients of renal transplants. ${ }^{9}$ The results also compare favourably with those of other studies where the yield from bronchoalveolar lavage has been compared with that from transbronchial biopsies. ${ }^{101131}$ In our series, although eight of the 40 lavages had a negative result, tissue investigation by open lung biopsy (one patient) and postmortem examination (two patients) also failed to give a diagnosis either histologically or by culture. The negative results in these three patients should therefore be accepted as true negatives. Necropsy in a fourt $\overrightarrow{3}$ patient did, however, allow a histological diagnosis to be made, but again no causative organism was isof lated. Four of the patients with negative results from lavage recovered rapidly after bronchoscopy and $\overline{\mathrm{m}}$ presumptive diagnosis of a treated bacterial infection was made. This seems a reasonable assumption $\mathfrak{x}^{3}$ they had all been started on empirical broad spectrure antibiotic treatment at the start of their illness and dit not have bronchoscopy immediately.

Within the infective group the identification of viral cause can be particularly difficult. The use of monoclonal antibodies in a double layẹp immunofluorescence technique has improved th $\vec{s}$ speed of diagnosis of cytomegalovirus infections. In our institution the DEAFF test has been found to have a specificity of $100 \%$ and a sensitivity of $80 \%$. $\frac{10}{9}$ DEAFF has also been performed on lavage materiat from patients with cryptogenic fibrosing alveolit\& and sarcoidosis and there have been no false positive $\vec{Q}$ These data, with the negative results obtained with saliva, support the contention that when cytomegalovirus is found in bronchial lavage fluid it mas be considered a true pathogen. Cytomegalovirus takes from five to 12 days to grow in conventional celf culture and this is too long to be of practical use. Th5 long incubation period also means that fungal or bac terial contamination of the culture is more likely. Cuñ tures were also lost owing to the toxic effect of the bronchoalveolar lavage material on the fibroblast $\vec{\delta}$ For many reasons therefore cell culture is an unsatisfactory method for diagnosing cyto megalovirus pulmonary infections in immun $\overrightarrow{0}$ compromised patients. Two of the DEAFF positive samples were also positive by direct staining. These were from patients with advanced disease and exten? sive chest radiographic changes. Although the sens tivity of direct staining was much lower than that found with the DEAFF technique, it has the advars tage of even greater speed as the results are availabk within five hours of bronchoscopy.

It is sometimes questioned whether the identification of fungi, such as Candida albicans, bronchoalveolar lavage fluid is a reliable indicator of their presence in the lung; but, in an immp nocompromised patient where no other pathogen has been isolated, we believe that a reasonable growth $O D$ candida from lavage fluid should be regarded significant, provided that the oropharynx is clear. 0

Not all patients had signs in the chest or abnorma radiographs at presentation, but important symp $p^{+}$ toms and signs leading to a clinical suspicion of pneư monitis were shortness of breath, cough, fever, and $\$$ reduction in gas transfer. In most of these patients of was still possible to recover a significant pathoge from the lower respiratory tract. A normal chest 
radiograph should not be a deterrent to investigation as those patients who are diagnosed and treated early will have a greater chance of recovery. We found that the prognosis for patients presenting with widespread diffuse changes and an arterial oxygen tension of $<8.0 \mathrm{kPa}$ while breathing air was extremely poor.

Overall survival in this group of patients was $33 \%$, a figure that compares favourably with results from other centres. Meyers et al ${ }^{5}$ reported a mortality rate varying from $63 \%$ for idiopathic pneumonia to $91 \%$ for cytomegalovirus pneumonia - that is, a survival rate under $10 \%$ among patients with a first episode of cytomegalovirus pneumonitis. In our series four out of 12 patients recovered from cytomegalovirus pneumonitis $(33 \%)$. This figure represents a threefold increase over the survival figures of Meyer $e t$ al, which is particularly notable since three of these patients survived two episodes. Survival after all episodes of pneumonitis is $50 \%$ in our series. Unfortunately, some patients developed a second episode almost immediately after appearing to recover from the first and subsequently died, but others developed a second episode only after a considerable interval, and for these patients recovery from a first episode represented an important gain. One patient was able to live a normal life for two years three months between episodes. Other studies of recipients of bone marrow transplants do not give details of second episodes on pneumonitis.

In conclusion, we would recommend bronchoalveolar lavage as a first line investigation in all recipients of bone marrow transplants developing evidence of pneumonitis.

We are pleased to acknowledge close collaboration with Dr Roger Sage of the Department of Microbiology and Dr P Griffiths of the Department of Virology, Royal Free Hospital. HJM received support from Bencard.

\section{References}

1 Buckner CD, Meyers JD, Springmeyer SC, et al. Pulmonary complications of marrow transplantation: review of the Seattle experience. Exp Haematol 1984;12(suppl 15):1-5.

2 Meyers JD. Viral infections in marrow transplant recipients. In: Gale RP, ed. Recent advances in bone marrow transplantation. New York: Alan R Liss, 1986:214.

3 Cardozo BL, Hagenbeek A. Interstitial pneumonitis following bone marrow transplantation: pathogenesis and therapeutic considerations. Eur $J$ Cancer Clin Oncol 1985;21:43-51.

4 Neiman PE, Reeves W, Ray G, et al. A prospective analysis of interstitial pneumonia and opportunistic viral infection among recipients of allogenic bone marrow grafts. J Infect Dis 1977;136:754-67.
5 Meyers JD, Fluornoy N, Thomas ED. Non bacterial pneumonia after allogeneic marrow transplantation: a review of ten years experience. Rev Infect Dis 1982;4:1119-32.

6 Daniele RP, Elias JA, Epstein PE, Rossman MD. Bronchoalveolar lavage: role in the pathogenesis, diagnosis and management of interstitial lung disease. Ann Intern Med 1985;102:92-108.

7 Stover DE, Saman MB, Hajdu SI, Lange M, Gold J, Armstrong D. Bronchoalveolar lavage in the diagnosis of diffuse pulmonary infiltrates in the immunosuppressed host. Ann Intern Med 1984;101:1-7.

8 Kelley J, Landis JN, Davis GS, Trainer TD, Jakab GJ, Green GM. Diagnosis of pneumonia due to pneumocystis by subsegmental pulmonary lavage via the fibreoptic bronchoscope. Chest 1978;74:24-8.

9 Hopkin JM, Young JA, Turner JH, Abu D, Michael J. Rapid diagnosis of obscure pneumonia in immunosuppressed renal patients by cytology of alveolar lavage fluid. Lancet 1983;ii:299-301.

10 Stover DE, White DA, Romano PA, Gellene RA. Diagnosis of pulmonary disease in acquired immune deficiency syndrome (AIDS): role of bronchoscopy and bronchoalveolar lavage. Am Rev Respir Dis 1984;130:659-62.

11 Broaddus C, Dake MD, Stullbarg MS, et al. Bronchoalveolar lavage and transbronchial biopsy for the diagnosis of pulmonary infections in the acquired immuno-defficiency syndrome. Ann Intern Med 1985;102:747-52.

12 Griffiths PG, Panjwani DD, Stirk PD, et al. Rapid diagnosis of cytomegalovirus infection in immunocompromised patients by detection of early antigen fluorescent foci. Lancet 1984;ii:1242-5.

13 Sloane JP, Depledge MH, Powles RL, Morgenstern GR, Trickey BS, Dady PJ. Histopathology of the lung after bone marrow transplantation. $J$ Clin Pathol 1983;36:546-54.

14 Winston DJ, Gale RP, Meyer DV, Young LS. Infectious complications of human bone marrow transplantation. Medicine (Baltimore) 1979;58:1-31.

15 Prentice HG, Blacklock HA, Janossy G, et al. Depletion of $\mathbf{T}$ lymphocytes in donor marrow prevents significant graft-versus-host disease in matched allogeneic leukaemic marrow transplant recipients. Lancet 1984;i:472-6.

16 Blacklock HA, Griffiths PG, Stirk P, Prentice HG. Specific hyperimmune globulin for cytomegalovirus pneumonitis (letter). Lancet 1985;ii:152-3.

17 Shepp DH, Dandliker PS, De Miranda P, et al. Activity of 9-[2-hydroxy-1(hydroxmethyl)ethoxymethyl] guanine in the treatment of cytomegalovirus pneumonia. Ann Intern Med 1985;103:368-73.

18 Puksa S, Hutcheon MA, Hyland RH. Usefulness of transbronchial biopsy in immunosuppressed patients with pulmonary infiltrates. Thorax 1983;38:146-50.

19 Leight GS, Michaelis LL. Open lung biopsy for the diagnosis of acute, diffuse pulmonary infiltrates in the immunosuppressed patient. Chest 1978;73:477-82.

20 Cunningham JH, Savala DC, Corry RJ, Keim LW. Trephine air drill, bronchial brush, and fibreoptic transbronchial lung biopsies in immunosuppressed 
patients. Am Rev Respir Dis 1977;115:213-20.

21 Davis GS, Kelley J. Invasive techniques for the diagnosis of respiratory infections. Clinics Lab Med 1982;2: 269-83.

22 Coleman DL, Dodek PM, Luce JM, Golden JA, Gold WM, Murray JF. Diagnostic utility of fibreoptic bronchoscopy in patients with pneumocystis carinii pneumonia and the acquired immune deficiency syndrome. Am Rev Respir Dis 1983;128:795-9.

23 Kalinske RW, Parker RH, Brandt D, Hoeprick PD. Diagnostic usefulness and safety of transtrachael aspiration. $N$ Engl J Med 1967;276:604-8.

24 Spencer DC, Beaty HN. Complications of transtracheal aspiration. $N$ Engl J Med 1972;286:304-5.

25 Davidson M, Tempest B, Palmer DL. Bacteriologic diagnosis of acute pneumonia: comparison of sputum, transtracheal aspiration and lung aspirates. JAMA 1976;235:158-63.

26 Anderson HA, Fontana RS. Transbronchoscopic lung biopsy for diffuse pulmonary diseases: technique and results in 450 cases. Chest 1972;62:125-8.

27 Flick MR, Wasson K, Dunn LJK, Block AJ. Fatal puE monary haemorrhage after transbronchial biops through the fibreoptic bronchoscope. Am Rev Respep Dis 1975;111:853-6.

28 Zavala DC. Pulmonary haemorrhage in fibreoptic trans bronchial biopsy. Chest 1976;70:584-8.

29 Pearce JG, Patt NL. Fatal pulmonary haemorrhage afte $\vec{D}$ percutaneous aspiration lung biopsy. Am Rev Respir Dis 1974;110:345-9.

30 Wallace JM, Batra P, Gone H jun, Ovenfors CO. Pes cutaneous needle aspiration for diagnosing pnet? monitis in the patient with acquired immunodeficienci syndrome (AIDS). Am Rev Respir Dis 1985;131: 389-92.

31 Williams D, Yungbluth M, Adams G, et al. The role of fibreoptic bronchoscopy in the evaluation of immuno compromised hosts with diffuse pulmonary infiltrates. Am Rev Respir Dis 1985;131:880-5. 